6th Sample.

Purchased at the shop of-Mr. Roberi Issot, 89, Briggate. GENUINE.

7 th Sample.

Purchased at the shop of-Mr. W. Coghlan, 143, Briggate. Grinurve.

8th Sanple.

Purchased at the shop of-Mr. S. Stead, 7, Holbeck-lane. Genuine.

$9 t \pi$ Sample.

Purchased at the shop of-Mr. R. Procter, 23, Holback-Iane. GENUINE.

$10 t h$ Sample.

Purchased at the shop of-Mr. Whittaker, Holbeck-lane. Genoine.

11th Sample.

Purchased at the shop of-Mr. W. Middleton, Holbeck-lane. GENUINE.

12th Sample.

Purchased at the shop of-Mr. S. Stead, 66, Sweet-street. Genunne.

13th Sample.

Purchased at the shop of--Mr. W. B. Duce, 68, Sweet-street. GENULNE.

$14 t h$ Sample.

Purchased at the shop of-Mr. Younghusband, Sweet-street. GeNUINE.

15 th Sample.

Purchased at the shop of-Mr. Winpenny, corner of Sweetstreet and Meadow-lane.

Genuine.

16th Sample.

Purchased at the shop of-Mr. G. Cooke, 15, Meadow-road. GENUINE.

17 th Sample.

Purchased at the shop of-Mr. Edward Suddick, 9, Waterlane.

Geavuine.

18th Sample.

Purchased at the shop of-Mr. Greenwood, 1 Hunslet-lane. GenUINE.

\section{GROUND GINGER.}

$19 t h$ Sample.

Purchased at the shop of-Mr. Nathan Bake, 8, Bridge End. GeNuIne.

20 th Sample.

Purchased at the shop of-Mr. Mallorie, 14, Bridge End. Genuine.

21st Sample.

Purchased at the shop of-Mr. James Wilson, 2, Briggate. Adulterated with MUSTARD-HUSK.

22nd Sample.

Purchased at the shop of--Mr. George Nichols, 5, Briggate. GENuine.

$23 r d$ Sample.

Purchased at the shop of-Mr. Robert Issott, 87, Briggate. GENUINE.

24th Sample.

Purchased at the shop of-Mr. W. Coghlan, 143, Briggate. "Fulon's Prepared Jamaica Ginger."

GeNuIne

25th Sample.

Purchased at the shop of-Mr. S. Stead, Holbeck-lane. Grinuine.

26th Sample.

Purchased at the shop of-Mr. S. Stead, 66, Sweet-street. GenoIre.
27 th Sample.

Purchased at the shop of-Mr. W. B. Duce, 68, Sweet-street. Genuine.

28 th Sample.

Purchased at the shop of-Mr. Winpenny, corner of Sweet. street and Meadow-lane.

Adulterated with a very large quantity of INDIAN-CORN MeaL.

29th Sample.

Purchased at the shop of-Mr. G. Cooke, 15, Meadow-road. GeNulne.

(To be continued.)

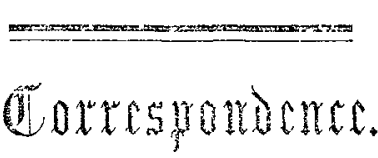

"Audi alteram partem."

\section{THE TREATMENT OF CHOLERA BY ARSENIC.} To the Elitor of THE LANCET.

SiR,-I perceive that your correspondent, Mr. Arthur Sarjeant, expresses his opinion, that we must etill look to Dr. Black as "the real patron" of the treatment of cholera by arsenic. That he is a patron of this specific and successful method, there can be no question, from the excellent account he has rendered of it in your pages; but that he is the originator of it, I again respectfully deny. N'evertheless, let that pass. It affords me much pleasure to find that he has wisely adopted this plan, and I.hope it will (through his additional advocacy) become universally aj)reciated should another epidemical visitation unfortunately give us occasion again to resort to its aid. I may just observe, en paseant, that the choleraic cases in which I used this remedy in 1819 were exchsively treated by the liquor potass a arsenites from beginning to end. Indeed at that time I was not at all aware of the great eficacy of minute doses of aconite in some of the earlier stages of this disease. Mr. Sarjeant appears further desirous of ascertaining from me the grounds on which I "depended" for the beneficial results, and what I consider to be "its curative mode of action." Now, $\mathrm{Sir}$, this is a large question, into which I cannot fully enter without a much greater "redundancy of expression" than may possibly be consistent with the many urgent demands upon your valuable space. At the same time I would observe, that the sublime object of our art should be the restoration of lost mental and physical health, by being a means so to relieve the afflicted as not to punish them, - in the language of $A$ sclepiades of old, to cure "citu, tuto, et jucunde," the actual accomplishment of which, I apprehend, is the ne plus ultra of the science and practice of medicine. The true physician, whose sole aim is to perfect his art, can avail himself of no mine of information so rich and exhaustless, respecting medicine, as-Firstly. What is the pure action of each by itself in the healthy body? Secondly. What do clinical observations of its action in this or that disease teach us? We know that Nature acts according to eternal and invariable laws, without so much as asking "by your leave." To write abstruse and complicated prescriptions, and several in the course of the day, which is not unfrequently done, is the climax of "empiricism." Nature loves simplicity, answers only when properly interrogated, and often effects much with one remedy, whilst we effect nothing with many. Let us seek to devoutly imitate her, as the direct way into the holy temple of art and science. To my own mind, to say that a small dose of medicine is practically sufficient and answers better than any amount of combination, is simply to state a plain fact. Every one is, $\mathrm{I}$ think, bound in common honesty and candour to give his own personal testimony to the truth. The experiment is not insuperably difficult. Let others try it, as I have done, and abide by the issue. I do not, however, affect to explain how cures are exactly wrought in every instance of cholera by small doses of arsenic. More is in vain, when less will serve, says Sir Isaac Newton, and the hitherto stationary condition of therapeutics may be said to have arisen from the utter want of simplicity in the method ordinarily pursued. Surely your correspondent does not mean to imply that because he does not understand the modus operandi or rationale of every plain matter of fact, ergo, he does not believe it. If this be his idea, I fear he believes very little; for I venture to assert he does not accurately understand one in a hundred of the phenomena which are perpetually occurring in his own 611 
mind and body, and which encompass him on every side. As the human race has advanced in intelligence and civilization, the various sciences have followed in its wake, that of medicine, however, ripening with a much slower growth.

Some two hundred and fifty years ago, Sir, Kepler caught a glimpse of the laws which worlds obey. Since then, Newton, Clairaut, Euler, and D'Alembert have so successfully studied the nature and operation of those laws, that Adams and Leverrier have been led throngh their expositions to the triumphant solution of the problem, "to find an unseen body by its effects on others that can be seen." Since then, also, even the erratic motions of the stars have been measured by quantities that are but fractions of the spider's line, and their numbers registered by terms that the widest capacity of the mathematician fails to apprehend, and shall the deep recesses of the healing process never yield up the secrets of its innermost life and mode of action? If there is any general principle of cure, that principle must express some relation between the medicine and the disease; and in order that it may be a principle of cure in any practical sense, it must exhibit such a relation between the disease and its remedy that an examination of the former shall enable us to select the latter. Nothing can be known to man except by means of some phenomena cognisable by his senses: these phenomena represent its properties. During the existence of any disease, its signs and symptoms are its only sensible representatives, whether these changes take place in structure or function. Now, any principle of cure, I submit, must express some relation between the properties of a disense and the medical character of a drugthat is, the character of its action on the living body; and a true principle, I take it, has this essential element in its nature-the element of progression; it enables us to pass from the known to the unknown. Such, for example, is the law of gravitation, by which the astronomer can predict what motions would take place in a group of heavenly bodies under any supposed conditions of mass, distance, and previous movement in each, at a given instant. Physiology and pathology, then, appear to me to teach us, that a drug, in order to acquire the character of a true remedial a cent in any given case of sickness, must invade the organism, as it were, by the same avenue as the morbific principle-the starting-point, so to speak, of the action of the drug, and that of the disease, must be identical. So soon as we are sure, I repeat, that the starting-point of both the drug-action and the disease is the same, (a truth which, by the way, was in succession stated by Hippocrates, Paracelsus, Van Helmont, Stahl, and many other eminent physicians, ) we may safely infer that these two forces will correspond (more or less) throughout the whole series of sensations and morbid changes which characterize their respective action in the human organism. We have it in our power, this point being well established, to apply with tolerable certainty an appropriate remedy to the unorbid phenomena observable in each in dividual case, in accordance with the fixed and immutable laws of physiological and pathological science-the phenomena developing themselves out of the starting-point which we are enabled to assign to them.

This, then, is the basis of what I humbly conceive to be a close approximation to a certain, positive, scientific system of therapentics. Although admitting that the reduction of the dose ought to have its limits, and that possibly beyond certain bounds all farther reduction becomes a matter of senseless jargon and an unmitigated imposition upon the credulity of our patients, it cannot be denied that even a very minute dose may possess a legitimate claim to the respectful regard of modern science. According to mathematicians, a point is so transcendently delicate that it is without all space--withont all length, breadth, height, or depth. Theoretically, therefore, the dose may be a mere point; practically, it may be one or more grains, a few drops of the mother tincture, or even part of a drop; and, under certain circumstances, I am prepared to affirm that this part may be administered with advantage, even when atomically small. A propos of the singular efficacy of minute doses of medicine, $I$ could mention many unexceptionable authorities. M. Bondin, a distinguished physician in the service of the French army, observes: "I have often obtained by a single dose of the hundredth of a grain of arsenic, the radical cure of fevers contracted either in Algeria or Senegal, and which had resisted divers means of various kinds, including large doses of quinine and change of climate." Now the hundredth of a grain is to the weight of a man of fifteen stone, as one is to one hundred and fifty millions. Is not this an atomic quantity of medicine to affect, so powerfully, so vast and disproportionate a quantity of matter? Not to multiply ex amples, I will merely add the testimony of Mr. Hunt, who remarks, in his interesting brochure on the Treatment of certain Intractable Chronic Skin Diseases, that "a fourth part of a "minim of Fowler's solution has, in a few weeks effected a permanent cure;" so that each of his doses contained only the four hundred and eightieth part of a grain of the white oxide of arsenic, or arsenious acid. Do not these facts teach us that each atom of the aggregated mass of a medical substance may be reduced to its isolated, and therefore (to us) invisible condition, by a singple process of division, and not of destruction? In physics, is it not an axiom, that bodies can be divided without limit, and that the molecule bas all the properties of the original body; and in chemistry, is it not a well-known fact, that combinations take place the more readily the more bodies are divided? And is it an unlikelihood that the vital principle (whatever that may be) has at least some share in the curative adaptation of a specific medicine to a specific malady, albeit it may not choose to be guided or influenced in anyway by a mere physical or chemical law, as is ordinary matter, in the test-tube of a chemist? The alone inseparable conditions would seem to be, a living organism in a state of disease acting in the same direction as the drug in health.

A small dose, then, I humbly submit, may be amply justified, and should no longer appear ridiculous before a tribunal of enlightened practitioners. "In stating this much, I may say with Dr. Black, it is not a "yielding to enthnsiasm," but to the valuable teachings of successful experience. Experience, indeed, has sanctioned what theory justifies and confirms. Not only has it done this in the case of the remedy adverted to, but it conld be readily shown, did I not fear to trespass on the patience of your numerous readers, that arsenic is only one of many medicinal agents which may, with equal justice, be placed in the same specific category. It is a well-known fact that the late lamented Dr. Pront first spoke of lactic acid as the probable materies morbi of acute rheumatism; and is it not equally true that this same acid, when introdueed into the system of animals by the peritoneum, will cause such pathological results as endocarditis and acute valvular disease? I am at present instituting some clinical experiments, with a view to ascertain its therapeutic value in analogons cases, and shall be much mistaken (judging from facts already in my possession) in my estimation of this "feeble acid," if it does not prove a considerable acquisition to our " armamentarium medicorum." An immense number of similar reports may be found scattered through the columns of your far-famed journal, such as ipecacuanba having been given successfully in asthma; copper in spasmodic affections; nux vomica in spinal disease; creosote in derangements of the stomach; sulphur in disenses of the skin; belladonna in scarlatina and the prevalent dipthe. rite; croups cured by aconite; mumps by mercury; pneumonic affections by phosphorns; tabes mesenterica, with spinal distortion, by carbonate of lime, and so on, almost ad infinitum. When the entire action of a medicinal substance will correspond with the consecutive phenomena of natural disease, then, and only then, I assume the drug to be a true remedial agent in the individual case; then, permit me to add, Sir, it will effect a speedy, safe, and permanent cure, provided such a re. sult be at all possible. There must, no doubt, be some limit to the attenuation of medicines, some degree of dilution, at which their power of acting ceases altogether; nevertheless, there is no human being entitled to say where that power ends, or what degree of attenuation of any medicine deprives it utterly of all therapeutic or curative influence.

I claim nothing for the views thus imperfectly advanced, but what is dne to every Englishman, a fair field and no favonr, and an quite ready to fight out the small-dose question, without a shadow of doubt as to the issue, (and, therefore, do not sheath my sword for lack of argument,) provided the contest be conducted as it becometh gentlemen, without the rash im. putation of unworthy motives, without discourtesy, and the other numerous vices, which usually degrade and dishonour controversy; for why, in the language of glorious old Spenser,

\section{"For why should witless man so much mis-ween}

In conclusion I beg to assure Mr. Sarjeant, who appears magnetically sensitive of what he calls "empiricism," that I ain neither $a$ blind and submissive follower of the doctrines of Hahnemann, nor an exclusive "homœopath" in the absurdlybigoted and restricted sense of that perverted term, but a physician at full liberty to prescribe medicines in all useful doses, according to the best of my knowledge and judgment, and anxious, also, to benefit my patients cito, tuto, et jucunde, to avoid every injury and obtain every advantage. With a readiness and a skill, in harmony with the growing intelligence of 
modern times, let us gladly avail ourselves of all the successful experience we can gather from every quarter, and cheerfully resort to every practice which science and observation commend, as sound and salutary, never forgetting, that from age to age in the world's history, the ardent followers of truth have uniformly been the calumniated few, pressing on to the achievement of other and yet more ennobling triumphs, well knowing that "ever the truth comes nppermost, ever is justice done." Let us also be grateful for that knowledge which Providence has already vouchsafed to send upon us, and always earnest in our endeavour for what light or help, patient, industrious, honest observation of Nature, may hereafter bring, till truth itself, in her own spotless and unsullied purity, shall have descended amongst us in the glory of its divine lineage, and won the homage of our hearts, as its irresistible and heaven-born birthright.

Liverpool, Dec. 1857.

I am. Sir, \&c.,

WM. HrTchman, M.D.

\section{To the Editor of The LANCET.}

SIR,-It is strange that the treatment of cholera by arsenic should have taken so many of our professional brethren by surprise. I have used that medicine in cholera and choleraic diarrhœa for seven years with great success, and I believe it has been employed as a remedy in that disease by a great number of medical men.

I think Mr. Sarjeant will find the grounds on which may be depended the beneficial results of the arsenical treatment very nearly satisfactorily explained in Dr. Black's second letter in your jonrnal of Oct. 17th.

I should prefer asking Dr. Hitchman, as he lays claim to be the originator of the arsenical treatment, to be good enough to inform us by what process of reasoning he was first induced to try arsenic in cases of cholera. He could not, I imagine, have accidentally hit on a medicine that has proved so successful in his and Dr. Black's hands.

As this medicine has proved itself almost a specific in cholera, why may not the hitherto undiscovered specific power in certain diseases of other drugs be brought to light, if the paths to such knowledge be laid open to the profession by those who have previously trodden them, as in the cases of Drs. Hitchman and Black in discovering the use of arsenic in the disease of cholera?

I am, Sir, yours respectfully,

King's Lynn, Dec. 1857. Johs J. W mitixg.

\section{EPIDEMIC MALIGNANT SORE-THROAT.}

To the Editor of TInE LANCET.

SrR,-I observe, in your journal of the 7 th Norember, that diphtherite has made its appearance in Essex; and, in that of the following week, I observe, further, that your correspondent at Billericay has given a description of the disease, but does not include any croup-like symptoms. We have lately had a visitation of the disease in this neighbourhood. It is likely that it is often confounded with quinsey, throat-fever, and croup with the first, becanse, commencing in some cases with slight febrile symptoms and external tumefaction of the cervical glands, it rapidily terminates, with sloughing about the pharynx, in death; with croup, from its taking on, in other cases, perhaps in the same house and from the commencement, a harsh, husky sound of the voice and respiration, with stridulous cough, the trachea being more involved than the pharynx; and in such a case a post-mortem examination has displayed a false membrane in the trachea, as in croup; but the close even of such a case, is without the severity of symptoms observable in true croup. Finally, it is confounded with throatfever, because that term seems to be applied, in some districts, to any febrile state complicated with ulceration of the tonsils, although $I$ believe it is more commonly restricted to the accompanying cynanche of scarlatina maligna. I notice the term because it occurs in the last Quarterly Rieport of the RegistrarGeneral.

It is unfortunate for the profession that the disease often fails to be recognised until suspicion is excited by its extreme mortality.

That diphtherite has some contagious quality would appear from the circumstance that, in a small village in an adjacent parish, five children died within a few days of each other, the whole of them being the offspring of two brothers and a nephew, living in three almost contiguous houses, and in hourly communication with each other during the period of illness in the house of either, The five children were attended separately by four medical men, and, the nature of the disease being early announced, the most energetic treatment was exhibited, but in vain. It was observed that during the existence of the disease several young persons and adults were attacked with slight symptoms of ordinary quinsey in the same village.

I could discover no cause for the origin of the disease in this village, unless it could have been in a sharp east wind which had just set in, after a long period of mild, moist, warm weather.

In one case, which has occurred more recently, I used the acetum cantharidis, immediately and extensively, over the neck and upper part of the thorax; persisted in the use of ipecacuanha wine, so as to maintain slignt nausea and diaphoresis; and used the nitrate of silver in solution locally to the throat, and, from the success obtained in this case, should be inclined, if I had another opportunity of treating the croup-like form of the disease, to thrust the solution into the larynx. I am, Sir, your obedient servant,

Helston, Cornwall, Nov. 1857. JAMES WEARNE, M.R.C.S.

\section{To the Editor of THE LANCET.}

SIR,-The prevalence of diphthérite induces me to suggest, through your pages, that opportunities of pathological investigation of this disease should be carefully used when they occur. The anatomical site of the effused lymph remains to be established. This has an important bearing upon the question of the performance of tracheotomy in the stage of suffocation as a means of relief. I have parformed the operation in one swch case, at the request of an accomplished plysician, and $I$ have assisted at its performance on another occasion under like circumstances. In neither instance did any benefit result. I am not convinced that the operation is advisable, or even to be justified in this disease. More exact knowle lge of its pathology is needed to set the question at rest.

I am, Sir, your obedient servant, ERNEST HART.

Upper Berkeley-street West, Hyde-park-square, Dee. 1857.

\section{To the Editor of THE LAxсET.}

SIR, - Having noticed in the last two numbers of THE LANCET some remarks upon the treatment of the Boulogne sore-throat, and having myself had six cases under my care, last spring, when it was very prevalent in this neighbourhood, and many died, I am induced to forward you an account of the treatment $I$ adopted, in the hope that it may prove as siccessful in the hands of others as it proved in mine. In all siz cases the same appearance was noticeable. The whole surface of the tonsils and the upper part of the pharynx were covered with deep white, aslay slongh, attended with great pain and difficulty in deglutition, and as the mischief advanced there was a thick and highly offensive discharge from the nostrils. The cases were marked by great prostration of strength and spirits, cold extremities, feeble and compressible pulse, and great disinclination for food, clearly indicating the supporting plan of treatment. Bark, with nitric acid, in large doses, was freely administered, and the strength sustained by a liberal use of port wine, beef-tea, and exgs. As a gargle, diluted sulphuric acid, in the proportion of half an ounce to the half pint of water, was found very useful. This line of treatment, attention being paid to the bowels, proved eminently successful, and I had the gratification of seeing all my patients recover.

I hope it may prove equally efficacious in the hands of others. who may feel disposed to give it a trial, for in some districts the mortality has proved most fearful. I may just add that the ages of those attacked varied from four to thirty-five years. of age. I am, Sir, your obedient servant,

Sutton Coldfield, Dec. 1857. Howard S. Ciravassf.

\section{THE INFLAMMATION AND BLOODLETTING CONTROVERSY.}

To the Editor of THE LANCET.

Sin, - I have read with great pleasure the remarks of $D r$. Strachan, in THE LANCET of Nov. 28th. on the inflammation and bloodletting question. From what I have seen of inflammatory diseases in various parts of England, I cannot but believe that there has been a remarkable change in them since the days of Cullen, and, indeed, since a period within the memory of the older members of the profession now living. Many gentlemen who have practised for twenty-five or thirty years, have assured me that for one case in which they bleed now they bled in twenty when they first commenced practice; 